\title{
Evaluation on physico-chemical and corrosion properties of anodized aluminium surface using sodium oxalate-sodium silicate bath at room temperature
}

\author{
M. Mubarak Ali* and S. Sathiya \\ Department of Chemistry, Chikkaiah Naicker College, Erode 638004 India
}

This study offers a comprehensive characterization of anodic surface layers formed in sodium oxalate electrolyte and systematically analyses the influence of addition of sodium silicate. $X$-ray diffraction, scanning electron microscope-EDAX and atomic force microscope studies are used to establish the correlation between electrolyte composition and anodized aluminium (Al). Stable anodic Al layers comprising tailored porosity and surface characteristics are achieved under optimized conditions, which exhibit corrosion current density $\left(I_{\text {corr }}: 1.04 \times 10^{-5} \mu \mathrm{A} \mathrm{cm}^{-2}\right)$ with high corrosion resistance of $7.03 \times 10^{2} \Omega \mathrm{cm}^{-2}$. Effect of anodization variables upon surface morphology, kinetic parameters, microstructural characteristics and thickness of anodized $\mathrm{Al}$ is evaluated. Gradient distribution of $\mathrm{Si}$ and $\mathrm{O}$ also indicates the relative content of silicate as illustrated by EDAX. Interpreted results from electrochemical impedance spectra and Tafel analysis are well-matched with physico-chemical analysis. Stable anodic Al layers comprising tailored morphology with high corrosion resistance are achieved under optimized conditions.

Keywords: Aluminium, anodization, corrosion resistance, sodium oxalate, sodium silicate.

ANODIC oxidation of aluminium (Al) is a well-established method to protect its surface from corrosion that inevitably facilitates high technological value and a wide range of industrial applications ${ }^{1}$. It is well reported that poroustype film structures are developed in strongly acidic solution, and barrier-type films are obtained using weak electrolyte medium ${ }^{2,3}$. Besides, strongly acidic or basic electrolytic media hinder the growth of dense anodic oxide layer. To address this issue, anodizing Al in a mixed electrolyte bath has been proposed to generate corrosion-resistive films. Previous studies reveal that modified anodizing bath comprising mixed organic electrolyte can generate improved anodized $\mathrm{Al}^{4}$. Despite such studies, much less details about composition, morpho-

\footnotetext{
*For correspondence. (e-mail: mubarakscience@gmail.com)
}

logy, structure and growth mechanism of anodized $\mathrm{Al}$ are revealed using sodium oxalate as an electrolyte.

In the light of the foregoing, the present study examines surface morphology of Al using an anodizing bath comprising sodium oxalate and sodium silicate that modifies the microstructure and composition of Al oxide layer. Composition of sodium silicate as an additive greatly influences anodizing efficiency and characteristics of the anodic layer. The study aims to evaluate the effect of organic electrolytes on anodizing parameters such as concentration of additive in the electrolyte, process duration and applied voltage on the surface morphology and microstructure of Al anodic layers.

\section{Experimental procedures}

\section{Fabrication of anodic coatings}

High purity (99.999\% pure, AL104, Mettler-Toledo International Inc.) Al plate of thickness $0.1 \mathrm{~mm}$ was used. The pretreatment step was accomplished by following the procedure described elsewhere ${ }^{5}$. Briefly, Al was cleaned and degreased using an ultrasonicator in acetone, water and ethanol. Surface-cleaned Al samples were subjected to thermal annealing at $450^{\circ} \mathrm{C}$ for $30 \mathrm{~min}$ by etching with $5 \% \mathrm{NaOH}$ for $2 \mathrm{~min}$ at room temperature $\left(35^{\circ} \pm 1^{\circ} \mathrm{C}\right)$ to discard the native oxide layer. The resulting Al samples were subjected to electro-polishing in a mixture comprising perchloric acid-ethanol $(1: 3)$ under an applied voltage of $20 \mathrm{~V}$ for $3 \mathrm{~min}$. Samples subjected to the aforementioned treatment were anodized in a two-electrode configuration using a direct current power supply (Aplab model: $0-5 \mathrm{~A} / 30 \mathrm{~V}$ and $0-1 \mathrm{~A} / 120 \mathrm{~V}$ ) after determining weight $\left(w_{1}\right)$ of each specimen. The sample to be anodized acts as an anode, whereas graphite sheet is used as the cathode in an electrolytic bath comprising $7.5 \mathrm{~g} / 1$ sodium oxalate with and without sodium silicate additive. Concentration of additive was varied from 2 to $8 \mathrm{~g} / \mathrm{l}$. Anodic layer coatings obtained from anodizing bath comprising sodium silicate concentration of $0,2,4,6$ and $8 \mathrm{~g} / 1$ were designated as SO, SOSI1, SOSI2, SOSI3 and SOSI4 


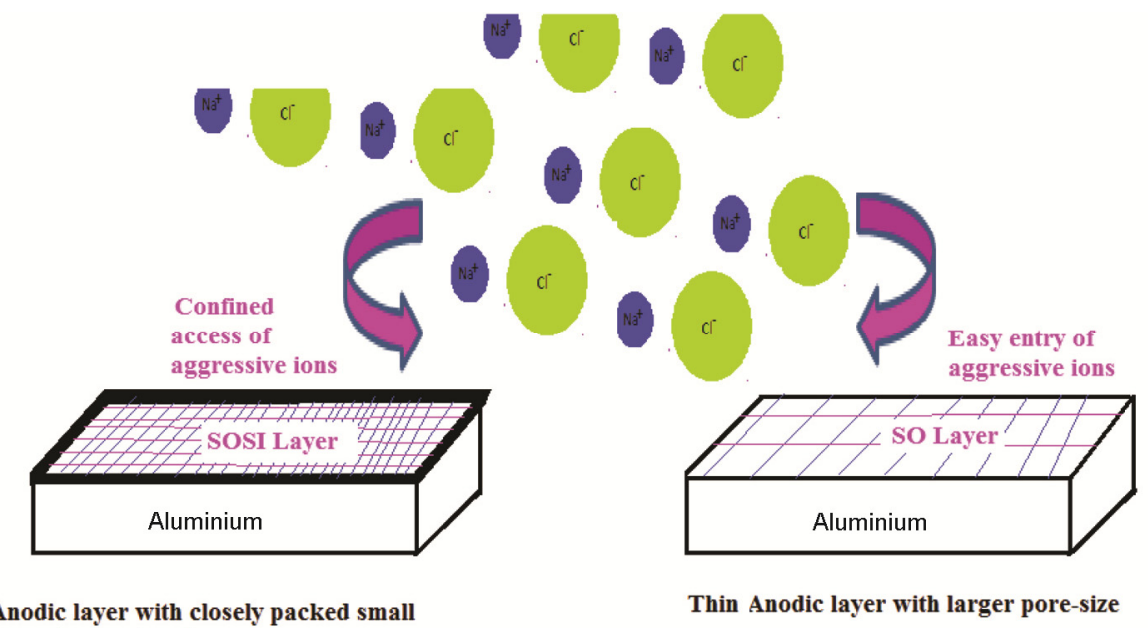

Anodic layer with closely packed small

Thin Anodic layer with larger pore-size

Scheme 1. Illustration of improved corrosion resistance of SOSI3 anodic layer.

respectively. SO was prepared for comparative studies. Anodized specimens were cleaned with deionized water followed by drying in $\mathrm{N}_{2}$ atmosphere and their weights were determined. The working surface under study was kept constant as $1 \mathrm{sq}$. cm, and rest of the surface was insulated using an epoxy resin. The scheme of the experiment is shown in Scheme 1.

\section{Characterization of the coatings}

The surface morphologies of anodic layers were examined by scanning electron microscope (SEM, FEI-QUANTAFEG 250, Japan) using a beam voltage of $20 \mathrm{kV}$ with magnification 10,000. Atomic force microscope (AFM) analysis was also done (ScaneAsyst-Bruker) by taping mode and energy-dispersive X-ray spectroscopic (EDs) studies were performed to analyse elemental composition and microstructure of the coatings. AFM images were plane-corrected and optimally Fourier filtered using SPIP (Image Metrology, Denmark) software. The crystallographic properties of the coatings were studied by powder X-ray diffractometer (XRD; Rigaku D/max 2550 V) using $\mathrm{CuK}_{\alpha}$ radiation at $45 \mathrm{kV}$ and $100 \mathrm{~mA}$. The average crystallite size was calculated from the line broadening of corresponding reflections according to Scherrer's equation.

$$
D=k \lambda / \beta \cos \theta,
$$

where $D$ is the average crystallite size $(\mathrm{nm}), \lambda$ the wavelength of X-rays, $k$ a constant taken as $0.9, \beta$ the full width at half maximum intensity and $\theta$ is the half diffraction angle.

Vickers microhardness indenter was used to quantify microhardness of the specimen. A coating thickness gauge (PosiTector 6000 thickness tester) was used for measuring coating thickness non-destructively. Microstructure was monitored by optical microscopy (XJL$230 \mathrm{~V} / 50 \mathrm{~Hz}$ ) after each polishing step.

Corrosion resistance of the coatings was evaluated by electrochemical impedance spectroscopy and Tafel polarization measurements in $3.5 \mathrm{wt} \% \mathrm{NaCl}$ at $30^{\circ} \mathrm{C}$ using an electrochemical workstation $\left(600^{\mathrm{TM}}\right.$ Potentiostat/ Galvanostat, Inc.). A three-electrode cell with coated aluminium as working electrode, $\mathrm{Ag} / \mathrm{AgCl} /$ saturated $\mathrm{KCl}$ as reference electrode and a platinum wire as counter electrode were used. All the experiments were conducted in aerated and non-stirred conditions. Using the method of extrapolation of anodic and cathodic sections, current density associated with corrosion $\left(I_{\text {corr }}\right)$ and resistance offered for charge transfer reaction $\left(R_{\mathrm{p}}\right)$ were determined (Table 1 ). $R_{\mathrm{p}}$ was determined using Stern-Geary equation as $^{5}$

$$
R_{p}=\frac{b_{a} b_{c}}{2.303 I_{\text {corr }}\left(b_{a}+b_{c}\right)},
$$

where $I_{\text {corr }}$ the corrosion current density, and $b_{c}$ and $b_{a}$ are the cathodic/anodic Tafel constants. $I_{\text {corr }}$ and $E_{\text {corr }}$ were obtained from the intercept of Tafel slopes. Electrochemical impedance (EIS) plots were recorded at frequencies between $100 \mathrm{kHz}$ and $0.01 \mathrm{~Hz}$ with amplitude of the sinusoidal signal of $5 \mathrm{mV}$. The impedance spectra were analysed by fitting with an appropriate Randel's equivalent circuit.

\section{Results and discussion}

\section{Anodizing process optimization}

Anodization of Al was carried out in sodium oxalate with and without incorporation of sodium silicate additive in 
Table 1. Corrosion parameters obtained from Tafel polarization studies on pure Al, SO and different SOSI anodic layers

\begin{tabular}{lcccc}
\hline Sample & $\begin{array}{c}\text { Open circuit } \\
\text { potential }(\mathrm{V})\end{array}$ & $\begin{array}{c}\text { Corrosion potential, } \\
E_{\text {corr }}(\mathrm{V})\end{array}$ & $\begin{array}{c}\text { Corrosion current, } \\
I_{\text {corr }}(\mu \mathrm{A} \mathrm{cm})\end{array}$ & $\begin{array}{c}\text { Corrosion resistance } \\
R_{\mathrm{p}}\left(\Omega \mathrm{cm}^{-2}\right)\end{array}$ \\
\hline Pure A1 & -0.699 & -0.698 & $7.59 \times 10^{-5}$ & $0.42 \times 10^{2}$ \\
SO & -0.570 & -0.571 & $5.87 \times 10^{-6}$ & $0.474 \times 10^{2}$ \\
SOSI1 & 0.189 & 0.208 & $6.29 \times 10^{-7}$ & $4.15 \times 10^{2}$ \\
SOSI2 & 0.761 & 0.753 & $8.18 \times 10^{-8}$ & $5.35 \times 10^{2}$ \\
SOSI3 & 0.857 & 0.866 & $1.04 \times 10^{-5}$ & $7.03 \times 10^{2}$ \\
SOSI4 & 0.672 & 0.722 & $3.04 \times 10^{-5}$ & $2.37 \times 10^{2}$ \\
\hline
\end{tabular}

order to understand the role of additive tuning towards microstructural features, morphology, microhardness and corrosion resistance. We observed that $7.5 \mathrm{~g} / 1$ sodium oxalate acts as a better electrolyte than concentrations of 3.7 and $15 \mathrm{~g} / \mathrm{l}$. Figure $1 \mathrm{a}$ presents the effect of sodium oxalate concentration on the thickness and growth rate of anodic layers.

The anodic layer which is obtained using $7.5 \mathrm{~g} / 1$ sodium oxalate exhibits highest thickness $(56 \mu \mathrm{m})$ and growth rate $(0.7 \mu \mathrm{m} / \mathrm{min})$, whereas dissolution of anodic layer predominates when the concentration of sodium oxalate exceeds $7.5 \mathrm{~g} / \mathrm{l}$. Similarly, at lower concentration $(3.7 \mathrm{~g} / \mathrm{l})$, the anodic layer formed is visibly non-homogenous. Therefore, $7.5 \mathrm{~g} / 1$ sodium oxalate was utilized for further anodization experiments (Figure $1 a-e$ ).

\section{Effect of additive concentration}

Al anodic coating obtained using mixed electrolyte bath comprising sodium oxalate and sodium silicate results in enhanced growth parameters after incorporation of sodium silicate as an additive. In order to get further insights about the kinetics of anodic layers, sodium silicate concentration was varied $(2,4,6$ and $8 \mathrm{~g} / \mathrm{l})$; Figure $1 b$ depicts the results. Maximum thickness $(76 \mu \mathrm{m})$ and growth rate $(0.85 \mu \mathrm{m} / \mathrm{min})$ were observed when the bath was maintained at $6 \mathrm{~g} / \mathrm{l}$; lower or higher concentration did not produce the desired thickness and growth rate. The conceivable reason for this behaviour is related to the change in $\mathrm{pH}$ and electrolyte in the presence of the additive, which results in non-uniform cooling near by the anode surface. When sodium silicate is added to the sodium oxalate solution, owing to change in the bath $\mathrm{pH}$, the rate of chemical etching on pre-formed anodic oxide layers is slowed down due to the released silicate anions. The $\mathrm{pH}$ of $7.5 \mathrm{~g} / \mathrm{l}$ sodium oxalate had changed from 8 to 9 after addition of sodium silicate. Nano-sized pores that are formed during anodization tend to combine due to increased electrolyte $\mathrm{pH}$ owing to the addition of sodium silicate.

However, the solution becomes more alkaline when we increase the concentration of the additive. So that the interior movement of the oxygen ions $\left(\mathrm{O}^{2-}\right)$ or hydroxide ions $\left(\mathrm{OH}^{-}\right)$towards the $\mathrm{Al} /$ aluminium oxide interface is enhanced. This will react with $\mathrm{Al}^{3+}$ ions which are around the surface of $\mathrm{Al}$ and begins to etch the coating that eventually deteriorates the growth kinetics. At low silicate concentration $(2-4 \mathrm{~g} / \mathrm{l}), \mathrm{pH}$ of the electrolyte bath is altered, which does not favour smooth structure due to pitting attack on the barrier oxide layer. Even though the coating formed from $8 \mathrm{~g} / \mathrm{l}$ silicate has greater thickness $(76 \mu \mathrm{m})$, distorted morphology is visibly noticed that also leads to the decrease in mechanical stability.

\section{Effect of anodization voltage}

To study the effect of voltage, anodization was carried out at optimum sodium oxalate and sodium silicate concentrations. Figure $1 c$ shows the resultant thickness obtained under varied applied voltage. Growth rate properties varied linearly with voltage up to $55 \mathrm{~V}$ and thereafter declined. This phenomenon could be explained through reactive steps involved dominantly ${ }^{6}$.

$$
\begin{aligned}
& \mathrm{Al} \rightarrow \mathrm{Al}^{3+}+3 \mathrm{e}^{-}, \\
& \mathrm{Al}^{3+}+3 \mathrm{OH}^{-} \rightarrow \mathrm{Al}(\mathrm{OH})_{3} .
\end{aligned}
$$

Water-splitting reaction near the electrolyte/oxide interface also occurs at this stage.

$$
2 \mathrm{Al}^{3+}+3 \mathrm{H}_{2} \mathrm{O} \rightarrow \mathrm{Al}_{2} \mathrm{O}_{3}+6 \mathrm{H}^{+}
$$

At lower voltage $(45 \mathrm{~V})$, the oxide layer has less thickness $(59.3 \mu \mathrm{m})$ and inferior mechanical strength owing to reduced rate of oxidation. In the presence of sodium silicate, stronger electric field increases with increasing voltage; however, at high applied voltage, dissolution of anodic layer predominates its formation. At high applied anodizing voltage, there is a high degree of hydration and ion incorporation, and thus dissolution of oxide layer is at the highest rate. At high voltage $(65 \mathrm{~V})$, dissociation of the ions increases resulting in the generation of more amount of silicate ions to form silicic acid, which in turn increases/decreases the $\mathrm{pH}$ of the electrolyte, which ultimately results in dissolution of the coatings. 

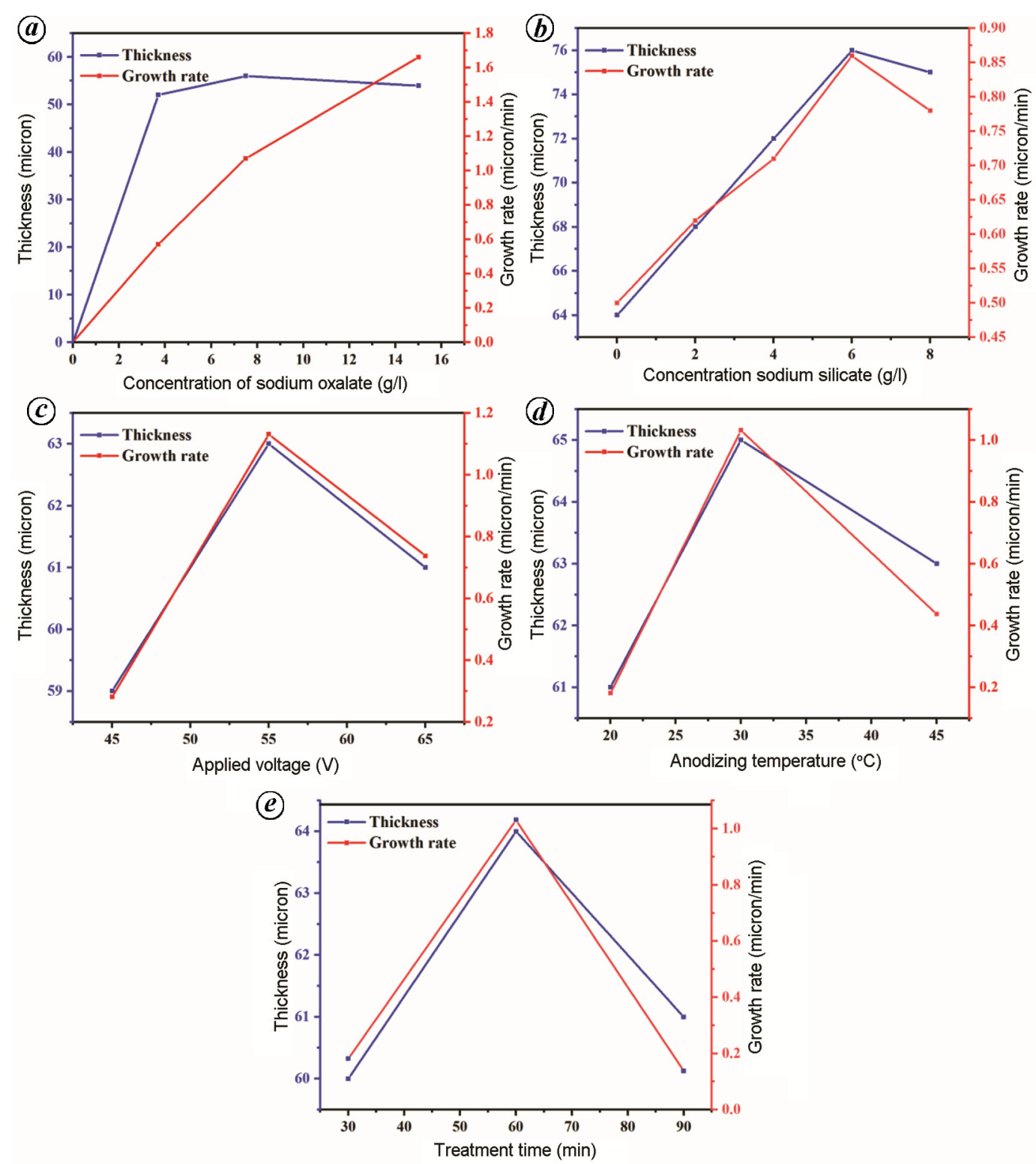

Figure 1. Effect of $(\boldsymbol{a})$ sodium oxalate concentration, $(\boldsymbol{b})$ sodium silicate concentration, $(\boldsymbol{c})$ anodizing voltage, $(\boldsymbol{d})$ anodizing temperature and $(\boldsymbol{e})$ anodization reaction time on growth kinetics of anodic aluminium layers.

\section{Effect of temperature}

Figure $1 d$ depicts the influence of anodizing temperature under anodizing voltage of $55 \mathrm{~V}$ in $7.5 \mathrm{~g} / 1$ sodium oxalate and $6 \mathrm{~g} / \mathrm{l}$ sodium silicate on the properties of the ceramic coating. The anodized layer obtained at room temperature $\left(35^{\circ} \pm 1^{\circ} \mathrm{C}\right)$ exhibits maximum growth rate $(0.42 \mu \mathrm{m} / \mathrm{min})$ and thickness $(63.3 \mu \mathrm{m})$. Anodizing temperature directly influences the rate of mass transfer of $\mathrm{O}^{2-}$ and $\mathrm{Al}^{3+}$ ions; inward diffusion of $\mathrm{O}^{2-}$ ions is facilitated when temperature is kept high $\left(40^{\circ} \pm 1^{\circ} \mathrm{C}\right)$. Correspondingly, outward diffusion of $\mathrm{Al}^{3+}$ ions from the metal surface is enhanced. Beyond the optimal temperature (room temperature), dissolution of anodized layer occurs preferentially than its construction leading to a porous anodic layer of lesser thickness.

\section{Effect of process duration}

Anodizing duration was varied from 30 to 90 min under anodizing voltage of $55 \mathrm{~V}$ in $7.5 \mathrm{~g} / \mathrm{l}$ sodium oxalate at room temperature to study the effect of anodizing process duration upon growth rate and coating ratio. The thickness and mechanical properties of the coating increase with the period of anodization up to $60 \mathrm{~min}$, after that it tends to turn down (Figure $1 e$ ). At the initial stage, the coating formation outweighs that of the chemical dissolution and it agrees with Faraday's law. The growth kinetics of the coating exhibit a linear dependence on the period of anodization. The dissolution of the coating prevailed owing to large amount of heat evolution causing growth kinetics to go down with period of anodization ${ }^{7}$. Hence, optimal 


\section{RESEARCH ARTICLES}

time of $60 \mathrm{~min}$ is required to entirely cover the anodized surface. Based on the aforementioned studies, anodization process using $7.5 \mathrm{~g} / 1$ sodium oxalate and $6 \mathrm{~g} / \mathrm{l}$ sodium silicate under applied voltage of $55 \mathrm{~V}$ for $60 \mathrm{~min}$ at room temperature is proposed to be optimal.

\section{Microstructural analysis}

Figure 2 reveals typical XRD pattern associated with pure Al, SO, SOSI1, SOSI2, SOSI3 and SOSI4. Emergence of monoclinic structure is noticeable at $39^{\circ}$ and $45^{\circ} 2 \theta$ scale might be due to the presence of the aluminium oxide compound $^{8}$. The degree of crystallinity has increased after annealing when compared with pure $\mathrm{Al}$, as demonstrated by the presence of sharp peaks at $39^{\circ}$. Predominantly, all anodized samples show peaks at $28^{\circ}, 30^{\circ}, 36^{\circ}$, $38^{\circ}, 42^{\circ}$ and $62^{\circ}$ which are correlated with $\delta$-alumina structure.

The $\delta$-alumina phase appears at approximately $2 \theta$ value of $20^{\circ}$ with $d$-spacing parameter of $3.97,3.90,3.248$, 3.240, 3.221 and $3.127 \AA$ for pure Al, SO, SOSI1, SOSI2, SOSI3 and SOSI4 samples respectively. Also, the phase appearing at approximately $2 \theta$ value of $40^{\circ}$ corresponds to the $d$-spacing parameter of $2.316,2.310,2.3065$, 2.3055 and $2.300 \AA$ for pure Al, SOSI1, SOSI2, SOSI3 and SOSI4 samples respectively. From $d$-spacing values, it is evident that the alumina phase becomes more crystalline in nature after anodization. On comparing $d$-spacing values of SO and SOSI samples, we find that addition of silicate into electrolyte bath influences crystallinity of the samples. Peak centred at $2 \theta$ value of $64^{\circ}$ corresponds to $\delta-\mathrm{Al}_{2} \mathrm{O}_{3}$ (JCPDS card: 88-1609). The concentration of other impurities in the oxide coatings remains low. Therefore it can be concluded that $\delta-\mathrm{Al}_{2} \mathrm{O}_{3}$ phases are present in the SOSI layers under study and the observed results are in agreement with those of our earlier studies ${ }^{9}$.

\section{SEM studies}

Figure 3 represents coating morphologies of SO, SOSI1, SOSI2, SOSI3 and SOSI4 anodic layers at various sodium silicate concentrations. It is clearly seen from the SEM images that the morphologies of SO and SOSI are different with respect to pore distribution, cracking property and compactness. When the concentration of sodium silicate is increased, the surface turns into particulate or nodular in nature, and invariably densely distributed, coordinated, fine grains are visible in the structure. Under low additive concentration (2 g/l, SOSI1 and $4 \mathrm{~g} / \mathrm{l}$, SOSI2), large pores appear, whereas at higher concentration (6 g/l, SOSI4), microcracks emerge with many chimps and holes. When the concentration is maintained optimum (8 g/1 SOSI3), a homogenous, nonporous microstructure is developed. Micro-sized cracks are detected with SOSI4, as a result of local heating effect on the anodized surface. Therefore, these SEM results illustrate that sodium silicate concentration is a decisive factor which determines structure, morphology and physico-chemical properties of the anodized layer.

\section{SEM cross-sectional studies}

Figure 4 shows the cross-sectional SEM images of SO and SOSI3. The thickness of both layers as measured from these images is almost similar to those using a coating thickness gauge obtained (Posi Tector 6000 thickness tester). The average thickness of SO and SOSI3 is 5.2 and $7.3 \mu \mathrm{m}$ respectively. It can be inferred that quality and thickness of the anodized layer show improvement after adding sodium silicate into the electrolyte bath. Closer examination of the images reveals a thin deposited layer of about $1-1.2 \mu \mathrm{m}$ thickness comprising three distinct regions, such as a dense barrier section at the $\mathrm{Al}$ /oxide interface, central porous section followed by a columnar part on the outer surface. Outward growth of the layer and retarded dissolution rate are the possible reasons for enhanced thickness exhibited by SOSI3.

\section{EDS analysis}

Compositional analysis of SO and SOSI3 anodized layers was carried out. Figure $5 a$ and $b$ shows their representative EDS spectra respectively. Major components of both coatings are aluminium and oxygen, as illustrated by peaks associated with $\mathrm{Al}$ at $1.486 \mathrm{keV}$ and that of oxygen at $2.307 \mathrm{keV}$. Additionally, presence of silicon and sodium peaks appearing at 1.86 and $1.0486 \mathrm{keV}$ in the SOSI3 spectrum indicates incorporation of sodium silicate into anodized alumina.

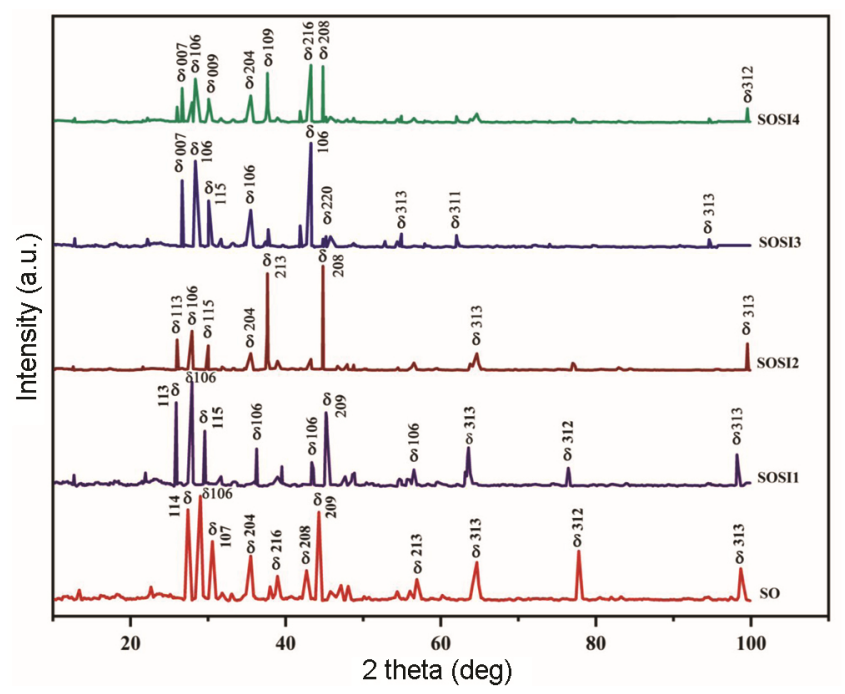

Figure 2. X-ray diffraction pattern associated with SO, SOSI1, SOSI2, SOSI3 and SOSI4 anodic layers. 

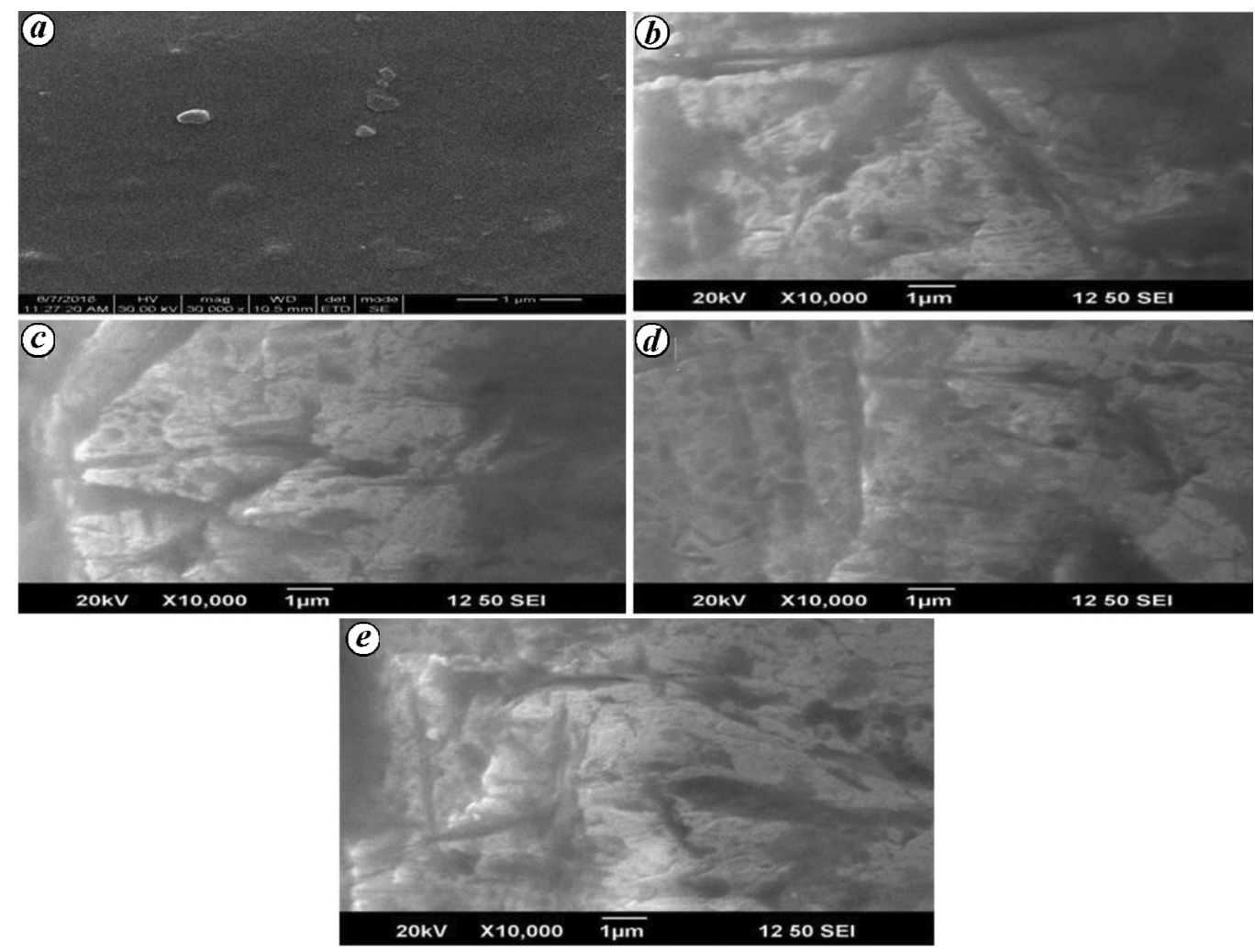

Figure 3. $a-e$, Scanning electron microscopic images of SO, SOSI1, SOSI2, SOSI3 and SOSI4 anodic layers.

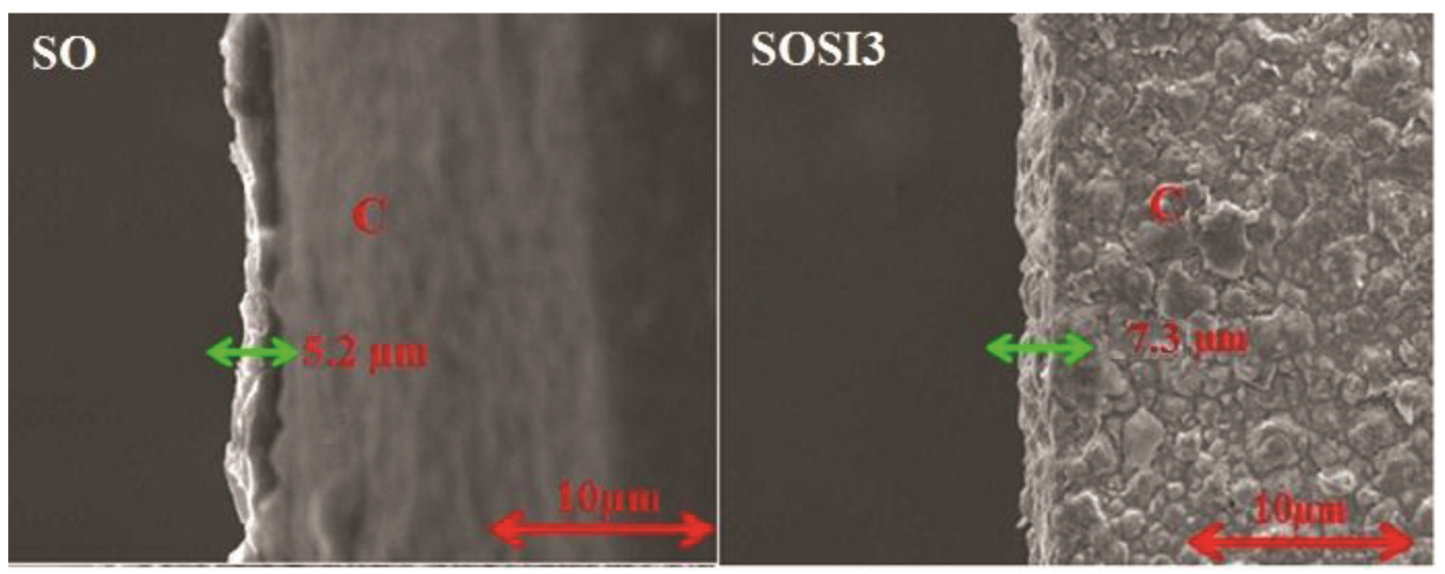

Figure 4. Cross-sectional SEM images of SO and SOSI3 anodic layers.

\section{AFM studies}

Figure $6 a-f$ displays the surface topology of pure $\mathrm{Al}, \mathrm{SO}$ and SOSI3 layers and their corresponding 3D images. The coating formed from pure sodium oxalate has an irregular growth of grains that are arranged at random locations; however, considerable undulations are observed with the SOSI3 layer. The average roughness factor associated with pure Al, SO and SOSI is $0.51,0.366$ and $0.033 \mathrm{~nm}$ respectively. The roughness associated with SOSI3 is lower than that of pure $\mathrm{Al}$ and $\mathrm{SO}$ surfaces. On evaluating the undulations in height profile, it is obvious that SOSI3 presents homogenous topographical features.

\section{Studies on microhardness}

Microhardness associated with pure Al (before anodization), SO and SOSI1, SOSI2, SOSI3 and SOSI4 samples was measured using Vickers microhardness tester (Figure 7). 


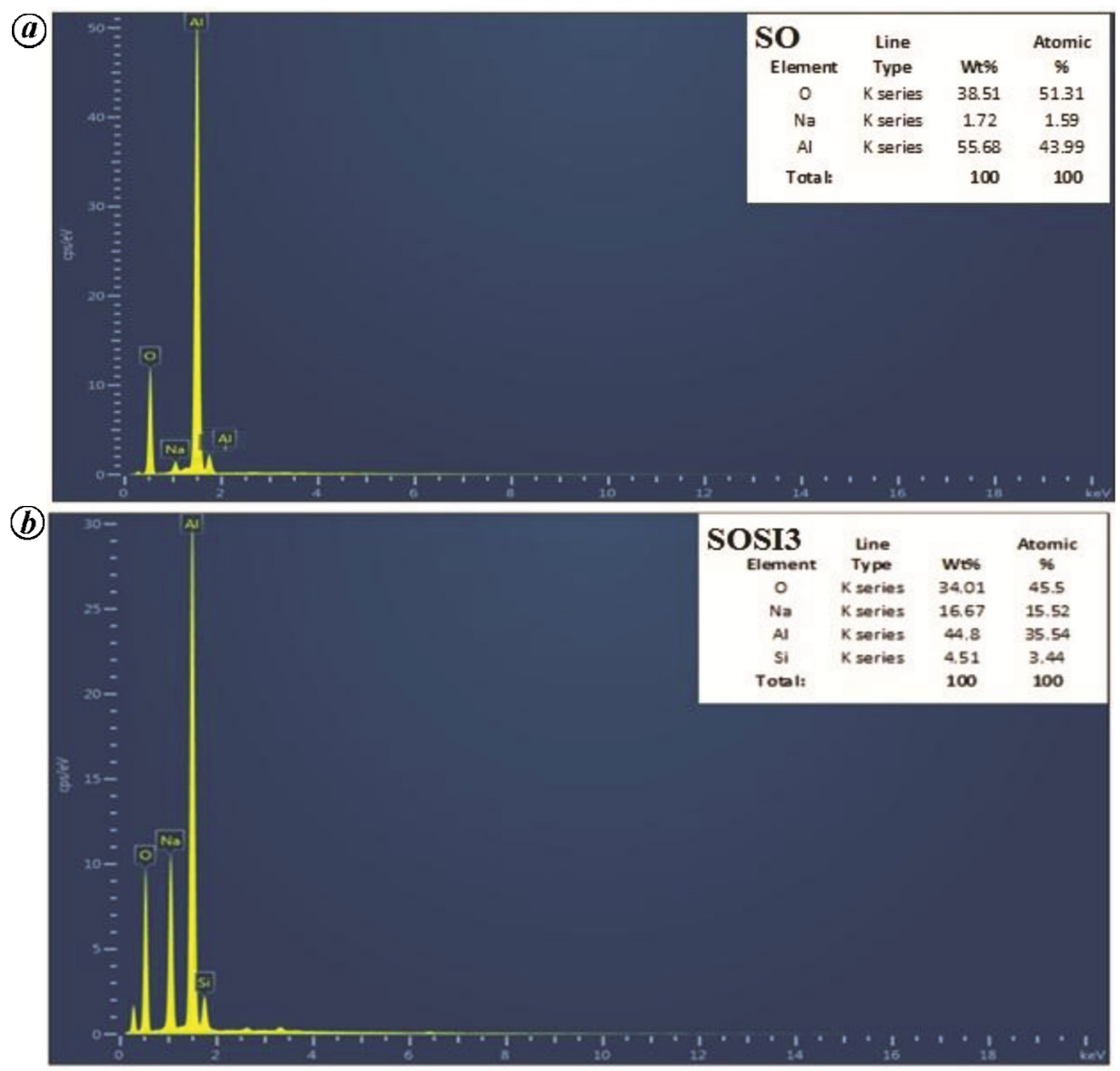

Figure 5. Representative energy dispersive X-ray spectroscopy spectra of SO (a) and SOSI3 (b) anodized layers.
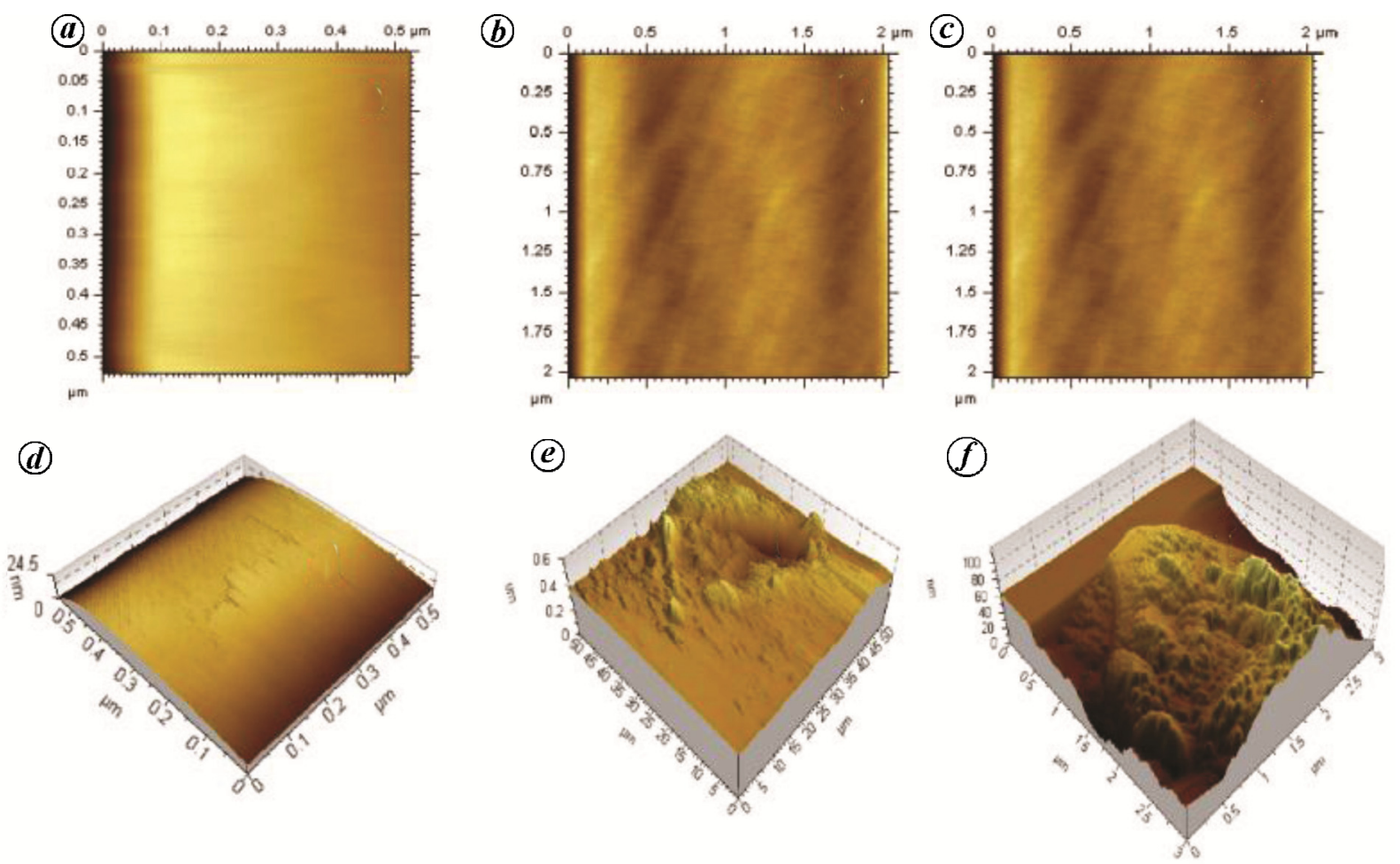

Figure 6. Topographical and related 3D images from atomic force microscopic analysis $(\boldsymbol{a}, \boldsymbol{d})$ pure Al, $(\boldsymbol{b}, \boldsymbol{e}) \mathrm{SO}$ and $(\boldsymbol{c}, \boldsymbol{f})$ SOSI3. 

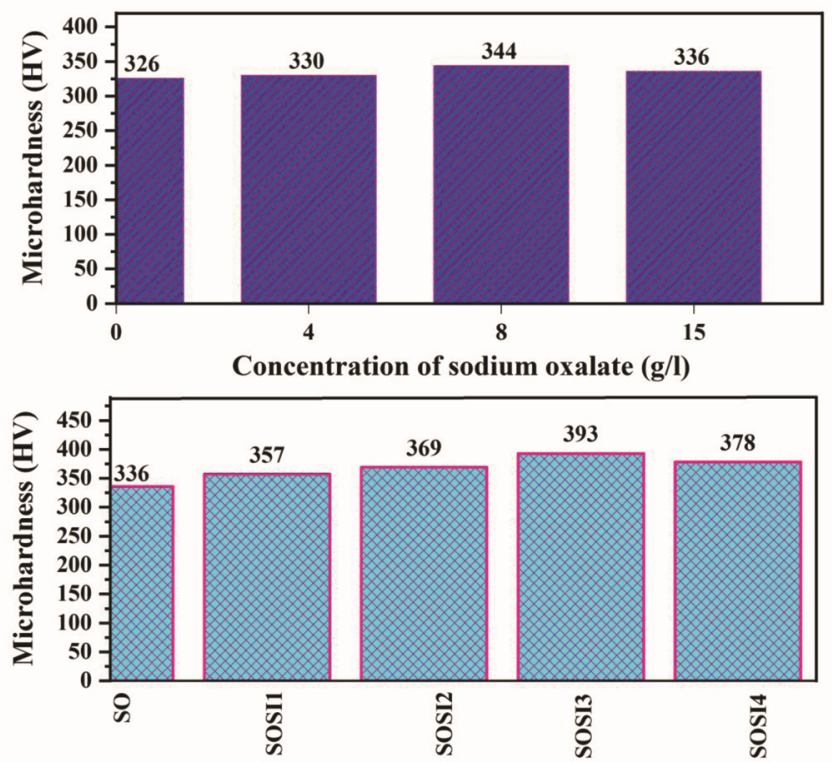

Figure 7. Influence of sodium oxalate and sodium silicate concentration on microhardness of anodic layers.

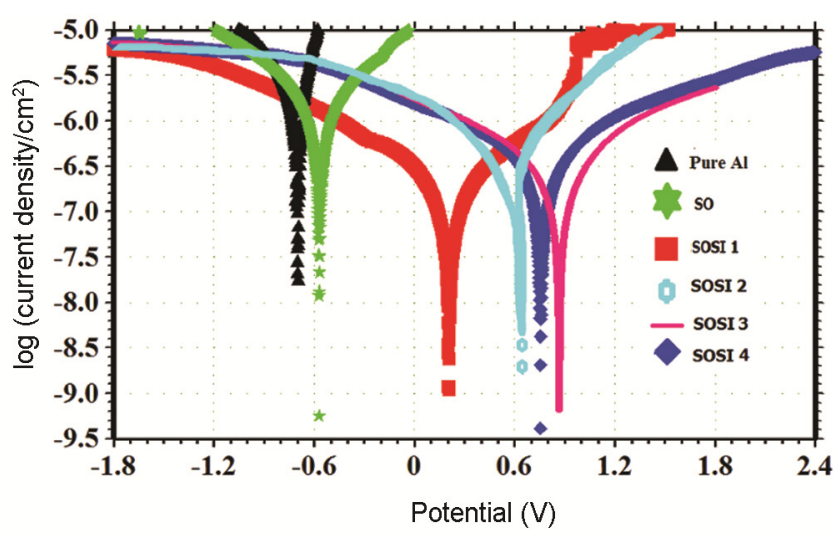

Figure 8. Tafel polarization plots for bare Al, Pure A1, SO, SOSI1, SOSI2, SOSI3 andSOSI4.

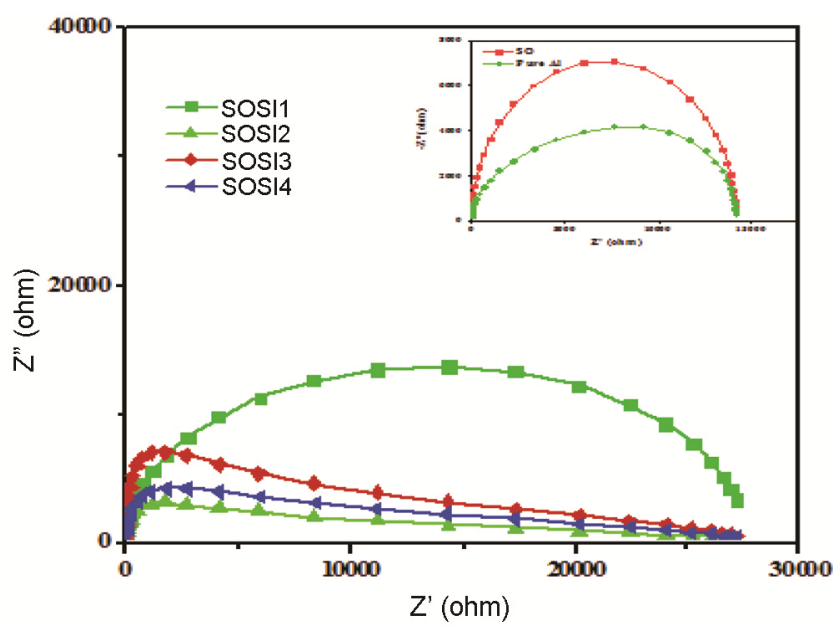

Figure 9. Nyquist plots for SOSI1, SOSI2, SOSI3 and SOSI4. (Inset) Plot for pure $\mathrm{Al}$ and $\mathrm{SO}$.
Microhardness was found to drastically improve due to anodization. Pure Al showed microhardness value nearly nine times lower $(40.56 \mathrm{HV})$ than anodized samples. On introducing sodium silicate into the electrolyte microhardness increased, obviously due to change in crystallite size of the anodized layer. The average microhardness values associated with SOSI1, SOSI2, SOSI3 and SOSI4 were 352, 356, 393 and 377 HV respectively.

\section{Tafel polarization studies}

Corrosion behaviour of different coatings was valuated by Tafel polarization studies carried out in $3.5 \% \mathrm{NaCl}$. Figure 8 shows polarization curves related to pure $\mathrm{Al}$, SO, SOSI1, SOSI2, SOSI3 and SOSI4. It can be deduced from the Tafel polarization studies that $I_{\text {corr }}$ related to pure $\mathrm{Al}$ is highest $\left(7.59 \times 10^{-5} \mu \mathrm{A} \mathrm{cm}{ }^{-2}\right)$, while passive behaviour is observed with the anodized samples ${ }^{10}$. Among all the samples, SOSI3 exhibited minimum $I_{\text {corr }}\left(1.04 \times 10^{-5}\right.$ $\mu \mathrm{A} \mathrm{cm}{ }^{-2}$ ), illustrating its high anti-corrosion characteristics. Addition of sodium silicate into the electrolyte solution resulted in thicker anodized layers. Therefore, thicker anodized layers (SOSI1, SOSI2, SOSI3 and SOSI4) display enhanced corrosion resistance depicted by lower corrosion current densities.

\section{Electrochemical impedance studies}

Impedance plots in Figure 9 show a characteristic depressed semicircle, implying deviation from ideal behaviour. Figure 10 shows an electrical equivalent circuit model for anodized Al used in this study. It consists of solution resistance $\left(R_{\mathrm{s}}\right)$ in series with, polarization resistance $\left(R_{\mathrm{ct}}\right)$ and double-layer capacitance $\left(C_{\mathrm{dl}}\right)$. Figure 9 evaluates electrochemical impedance spectroscopy characteristics of pure $\mathrm{Al}$ with $\mathrm{SO}$, SOSI1, SOSI2, SOSI3 and SOSI4 samples in $3.5 \% \mathrm{NaCl}$ obtained at open circuit potential after immersion of the samples for $500 \mathrm{~s}$. Impedance plots show diffusion behaviour at low frequencies, possibly due to formation of a protective thin oxide film. It is obvious that, high frequency part is correlated to protective anodic layer and low frequency part connected with different reactions takes place at the

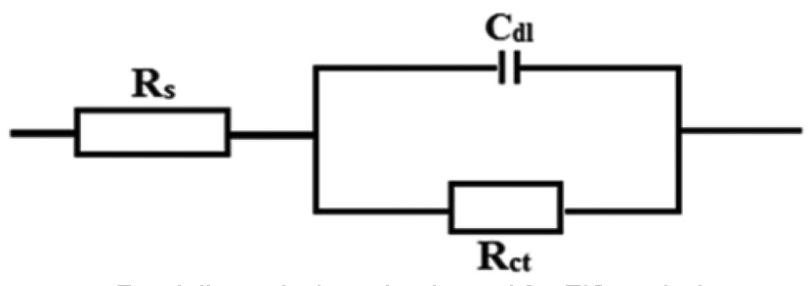

Randel's equivalent circuit used for EIS analysis

Figure 10. Simplified electrochemical equivalent circuit model fitted for impedance data analysis. 
Table 2. Corrosion parameters derived from electrochemical impedance spectroscopy Nyquist plot analysis associated with pure Al, SO and different SOSI anodic layers

\begin{tabular}{lccc}
\hline Sample & $\begin{array}{c}\text { Electrolytic resistance, } \\
R_{\mathrm{s}}(\mathrm{ohm})\end{array}$ & $\begin{array}{c}\text { Double layer } \\
\text { capacitance, } \mathrm{C}_{\mathrm{dl}}(\mathrm{F})\end{array}$ & $\begin{array}{c}\text { Charge transfer } \\
\text { resistance, } R_{\mathrm{ct}}(\mathrm{ohm})\end{array}$ \\
\hline Pure Al & 12.37 & $3.34 \times 10^{-6}$ & 83.63 \\
SO & 14.51 & $3.14 \times 10^{-6}$ & 876 \\
SOSI1 & 18.9 & $3.89 \times 10^{-6}$ & 6098 \\
SOSI2 & 30.13 & $2.76 \times 10^{-6}$ & 9902 \\
SOSI3 & 5.412 & $1.38 \times 10^{-7}$ & $4.06 \times 10^{7}$ \\
SOSI4 & 4632 & $1.64 \times 10^{-7}$ & $2.72 \times 10^{5}$ \\
\hline
\end{tabular}

$\mathrm{Al} /$ electrolyte interface through the defects and pores present in the anodic Al layer ${ }^{11}$. Table 2 depicts that pure Al exhibits lowest resistance $(83.63 \Omega)$ for corrosion among all the samples and corrosion resistance is greatly improved when sodium silicate is used for anodization. Therefore, SOSI1 (6098 $\Omega$ ), SOSI2 (9902 $\Omega)$, SOSI3 $\left(4.063 \times 10^{-7} \Omega\right)$ and SOSI4 $\left(2.72 \times 10^{5} \Omega\right)$ samples display high resistance compared to $\mathrm{SO}$, which demonstrates the protective role of silicate additive in surface corrosion.

\section{Conclusion}

In the present study, sodium oxalate has been used as an electrolytic medium to fabricate high corrosion-resistant anodic coating over $\mathrm{Al}$ surface. Effect of incorporating sodium silicate as an additive is systematically analysed. Anodizing experimental parameters such as applied voltage, reaction temperature, processing time and composition of the anodizing electrolyte have been evaluated. This study demonstrates that the introduction of silicate additive made a considerable impact on physico-chemical and electrochemical properties under optimized conditions. Future studies must focus on improving wear resistance of the anodized coating so as to utilize it for safely processing without hazardous by-products at a large scale.

1. Bajat, J. B., Milosev, I., Jovanovic, Z., Janc, R. M., Heinemann, I., Dimitrijevic, M. and Miskovic Stankovic, V. B., Corrosion protection of aluminium pretreated by vinyltriethoxysilane in sodium chloride solution. Corros. Sci., 2010, 52, 1060-1069.

2. Song, G., Corrosion behaviour of AZ21, AZ501 and AZ91 in sodium chloride. Corros. Sci., 1998, 40, 1769-1791.

3. Matykina, E., Arrabal, R., Mohamed, A., Skeldon, P. and Thompson, G., Plasma electrolytic oxidation of pre-anodized aluminium. Corros. Sci., 2009, 51, 2897-2905.
4. Zhang, Shi-Yuan, Xu, Qin, Wang, Zhi-Jun, Hao, Sheng-Zhen, Sun, Chun-Xin and Ma, Wen-Jin, Preparation and characterization of anodic alumina films with high-saturation structural colors in a mixed organic electrolyte. Surf. Coat. Technol., 2018, 346, 48-52.

5. Ma, D., Li, S. and Chenghao, L., Electropolishing of high-purity aluminium in perchloric acid and ethanol solutions. Corros. Sci., 2009, 51, 513-718.

6. Raj, V. and Mumjitha, M., Comparative study of formation and corrosion performance of porous alumina and ceramic nanorods formed in different electrolytes by anodization. Mater. Sci. Eng. $B, 2014,179,25-35$.

7. Mubarak Ali, M. and Raj, R., Formation and characterization of ceramic nanocomposite crystalline coatings on aluminium by anodization. J. Mater. Sci. Technol., 2013, 29, 595-602.

8. Ghrib, M., Ouertani, R., Gaidi, M., Ajoua Khedher, N., Ben Salem, M. and Ezzaouia, H., Effect of annealing on photoluminescence and optical properties of porous anodic alumina films formed in sulfuric acid for solar energy applications. Appl. Surf. Sci., 2012, 258, 4995-5000.

9. Mubarak Ali, M. and Raj, V., Formation and surface structural features of crystalline ceramic nanocomposite coatings on aluminum using lithium sulphate with silicate additive. Acta Metall. Sin. (Engl. Lett.), 2014, 27, 185-197.

10. Boinovich, L. B., Emelyanenko, K. A., Domantovsky, A. G. and Emelyanenko, A. M., Laser tailoring the surface chemistry and morphology for wear, scale and corrosion resistant superhydrophobic coatings. Langmuir, 2018, 34, 7059-7066.

11. Solomon, M. M., Umoren, S. A., Obot, I. B., Sorour, A. A. and Gerengi, H., Exploration of dextran for application as corrosion inhibitor for steel in strong acid environment: effect of molecular weight, modification, and temperature on efficiency. ACS Appl. Mater. Interfaces, 2018, 10, 2812-2819.

ACKNOWLEDGEMENTS. We acknowledge the characterization facilities at STIC, Cochin and corrosion studies at the Indian Institute of Technology-Madras, Chennai.

Received 18 June 2019; revised accepted 27 September 2019

doi: $10.18520 / \mathrm{cs} / \mathrm{v} 118 / \mathrm{i} 2 / 234-242$ 